\title{
The Use of Paper in Everyday Student Life
}

\author{
David M. Nichols \\ Department of Computer Science \\ Waikato University \\ Hamilton, New Zealand \\ $+6478385130$ \\ dmn@cs.waikato.ac.nz
}

\author{
Sally Jo Cunningham \\ Department of Computer Science \\ Waikato University \\ Hamilton, New Zealand \\ +6478384402 \\ sallyjo@cs.waikato.ac.nz
}

\begin{abstract}
The information we encounter in modern life, in developed countries, is a hybrid of the physical and the digital. Personal archiving tools allow users to capture and retrieve aspects of their everyday lives in digital form. In this paper we use a diary study of students' interactions with paper-based information to inform the design of such archiving tools.
\end{abstract}

\section{INTRODUCTION}

The information we encounter in modern life, in developed countries, is a hybrid of the physical and the digital. Although the digital portion of our lives has been growing rapidly information encoded in physical objects, predominantly on paper, remains an important element of our environment. Predictions that paper would disappear from our work environments have been shown to be premature [14] and studying our existing activities has led to useful insights into the creation of new digital applications (e.g. [15]). In this paper we follow this approach in using a diary study to investigate how paper functions to convey information in everyday life. In exploring these paper-based activities we aim to contribute to the requirements for personal archiving tools.

We outline recent work on personal archiving and then describe the study. Section 4 summarizes the data; we then discuss the results and conclude with possible future work.

\section{BACKGROUND}

Personal archiving of the information we encounter comprises both the preservation of digital items [15] and the digitization of physical items. As capture devices improve and storage costs decline it is "becoming possible to capture and store electronic records of many of an individual's life activities" [6].

One of the most well-known of these life-logging [6,13] projects is MyLifeBits [4] which combines data capture (through photographs, video, activity monitoring tools etc.) and information retrieval tools to help access the resulting multimedia documents. The SenseCam $[4,13]$ illustrates the integration of photographs (both passive and actively captured) with sensor data such as location providing a rich stream of metadata-enhanced multimedia. It seems reasonable to project that future devices will include video [7], audio [12], physiological data such as human movements [7] and heart rates, and interactional data from communication with other devices.

Technically we can capture much data: should we aim to capture everything we can? "We never regret capturing; but we often regret not capturing more. Storage space is essentially free and we can always add software to filter out less interesting items" [4]. It is often difficult to predict which stored items might become valuable at some time in the future [9]: "the most mundane details can bring great joy when they are viewed from distance of 30 years ... When those moments were stored, it was not clear that it was these characteristics that would come so highly valued" [11]. These observations support a 'capture everything' approach. However the history of computer-supported cooperative work shows that shifting such an attitude from individual to widespread social use may not be straightforward.

Much work on life-logging concentrates on existing digital information [13,15] (e.g. email, digital images) with less emphasis on everyday physical objects. A large component of this physically-encoded information is in the form of paper: in books, letters, newspapers, receipts etc. In 2000 Liu and Stork noted: "Paper remains the most popular document medium because of its credibility, tangibility, ease of use, portability, and compatibility ...We predict a long-term coexistence of paper and electronic documents" [8]. Although digital information storage has grown rapidly this view still seems applicable today.

Research on the use of paper has often focused on work environments [14] with typical results emphasizing the importance of context information, the costs of using existing document management systems and the use of visual-spatial techniques for structuring physical documents [2]. In one study some "interviewees stated that 'true memories' can not be saved electronically, but with technology we can provide aid for remembering certain key elements of the event" [11]. However, we believe there is scope for greater understanding of everyday physical objects, particularly paper, within the life-logging domain and that work in this area can guide the development of both capture devices and retrieval tools.

\section{METHODOLOGY}

Personal archiving has been addressed using various methodologies: individual case study [4], prototyping [11,13], interviewing [11]. We chose the complementary method of a diary study on daily encounters with paper-based information. Diary studies are useful in capturing the "little experiences of everyday life" [16], as participants literally make diary entries detailing their activities related to a topic or task. The advantage of a diary study - done conscientiously-is that it provides a record of events as they actually occur, rather than the retrospective (and possibly faulty) recollections elicited in interviews [1]. 


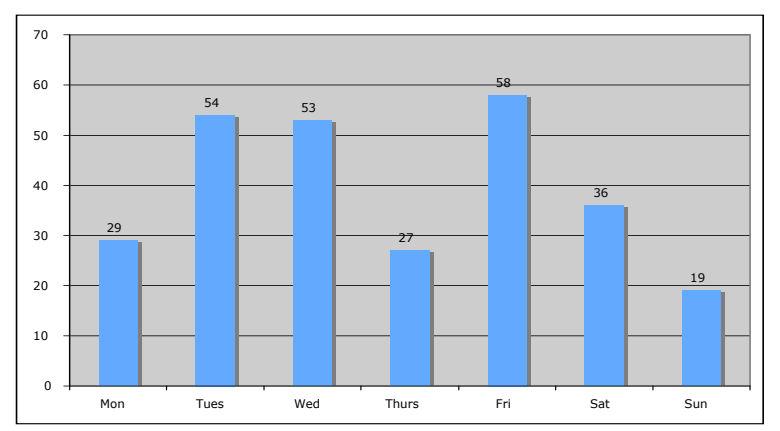

Figure 1. Days of week for diary entries.

\subsection{Data Collection}

Participants for this study were drawn from a third year university course on Human-Computer Interaction (the diaries were maintained as part of an assignment). The students were given a paper diary form with instructions to record encounters with information on paper (excluding the diary itself). Examples of paper information encounters provided included receipts, bus tickets, lecture notes, newspapers, magazines, menus, forms, and letters. Specifically, the participants were asked to record: date

Table 1. Demographic details of participants.

\begin{tabular}{|l|c||l|l|}
\hline Gender & Count (\%) & $\begin{array}{l}\text { National } \\
\text { Origin }\end{array}$ & Count (\%) \\
\hline Male & $35(86.2 \%)$ & NZ & $10(25.6 \%)$ \\
\hline Female & $5(12.8 \%)$ & China & $23(60 \%)$ \\
\hline & & Other Asian & $5(12.8 \%)$ \\
\hline & & Other & $1(3 \%)$ \\
\hline \hline Age range: & $20-36$ years & Average age: & 23.6 years \\
\hline
\end{tabular}

and time of paper information encounter; location that participant encountered the paper (home, shop, cinema, etc); a description of the item (receipt, newspaper, letter, etc.); when the item was produced (generated in front of the participant, printed earlier); who produced the paper item; and what the participant did with the paper item: save it, throw it away, give it someone else, etc.).

Thirty-nine participants maintained diaries for periods ranging from one to three days (the participants were asked to maintain a diary for at least one day). The participants are typical of tertiary IT students in New Zealand: mostly male, young, and with a high proportion of students of international origin (Table 1). While this study is opportunistic and so does not claim to represent experiences of 'typical' university students, it can develop a rich picture of paper information encounters for this sub-group.

A total of 277 unique paper information encounters were recorded, with an average of 7.1 encounters per participant (median 7) and 3.1 encounters per person per calendar day (median 2). The minimum number of encounters in a day was 1 , and the maximum was 12. The diary entries were distributed across all seven days of the week (Figure 1), and the diaries were maintained during the teaching semester (so study-related paper interactions would be expected to occur). The time of day at which paper interactions occurred is shown in Figure 2; the encounters are distributed across the participants' waking day.

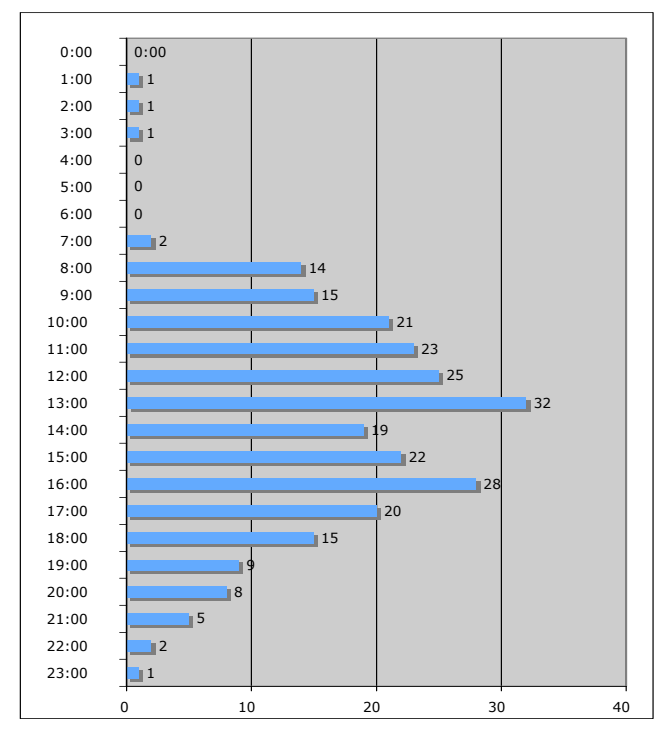

Figure 2. Hours of the day for diary entries.

\subsection{Limitations of Study}

Because diary entries are written 'on the go', as the activity under study unfolds, entries are typically terse. The level of commitment and effort required to create detailed and comprehensive records generally leads to significant attrition over the study [1]. We believe that the participants had a greater than usual sense of commitment to the process as the diary was a component of their course assessment. The students were able, however, to opt out of having their diaries included in the data used for this present paper, by emailing a third party to indicate this desire. The lecturers for the course did not know which students opted out of having their diaries analyzed for this present study until after the end of the semester; that is, a decision to opt out could not adversely affect a student's grade, and a decision to allow a diary to be analyzed could not favourably affect the student's grade. In this study, the compliance burden [1] was alleviated by: distributing a pocket-sized diary to participants; providing a category template on each page to structure responses; limiting the diary period to a single day; and requesting as few details about each encounter as was practical.

\section{FINDINGS}

A Grounded Theory approach was used to analyze the diary entries [5]: each descriptive field in the diary template was systematically reviewed to identify clusters of similar concepts, and then entries were 'coded' to tease out the themes discovered in the raw data. Inductive data analysis is particularly well suited to analyzing diary data because it allows patterns to emerge from the participants' free text entries. The challenge to researchers is to avoid imposing preconceptions in the analysis phase.

\subsection{Location of Encounters}

Table 2 identifies the categories of locations at which the paper information encounters occur, as well as the proportion of participants reporting at least one encounter at each location 
category. Nearly half of the diary entries concerned encounters with paper information in commercial environments (eg, a retail shop, bank, restaurant). The next largest category-over a quarter of entries - is domestic, which encompasses the participant's own residence as well as the homes of friends or family. Given that all the participants are part-time or full-time students, it is to be expected that University should appear as a source of encounters.

Table 2. Location of paper information encounters

\begin{tabular}{|c|c|c|}
\hline Location & $\begin{array}{c}\text { No. }(\%) \text { of diary } \\
\text { entries }\end{array}$ & $\begin{array}{l}\text { No }(\%) \text { of } \\
\text { participants } \\
\text { reporting this } \\
\text { location }\end{array}$ \\
\hline Commercial site & $135(48.7 \%)$ & $37(94.9 \%)$ \\
\hline Domestic & $75(27.1 \%)$ & $28(71.8 \%)$ \\
\hline University & $55(19.9 \%)$ & $24(61.5 \%)$ \\
\hline Bus / travel & $12(4.5 \%)$ & $6(15.4 \%)$ \\
\hline Total: & $277(100 \%)$ & \\
\hline
\end{tabular}

\subsection{Paper Document Types}

Table 3 breaks down the categories of paper document type encounter by location. Receipts are commonly issued at the end of a sales transaction, and so are strongly tied to commercial site encounters. Tickets and coupons are also frequently found or used in shops, or in the case of tickets used in bus travel.

Documents produced or consulted for university study include assignments (both draft and finalized for submission), lecture notes (primarily PowerPoint slides created by the lecturer), personal class timetables, and handouts such as sample exams. Participants mainly encountered these study-related documents at university (primarily in labs or lectures) or at home, as they reviewed lecture material or prepared assignments.

Table 3. Types of paper documents.

\begin{tabular}{|c|c|c|}
\hline Document type & Number (\%) & Location \\
\hline Receipt & $112(40.4 \%)$ & $\begin{array}{l}\text { Commercial (103); } \\
\text { University (6); Bus (2) }\end{array}$ \\
\hline Study-related & $55(19.9 \%)$ & $\begin{array}{l}\text { University (37); Domestic } \\
\text { (16); Commercial(1); Bus (1) }\end{array}$ \\
\hline Letter (postal) & $28(10.1 \%)$ & Domestic (28) \\
\hline Ticket/coupon & $20(7.2 \%)$ & $\begin{array}{l}\text { Commercial (10); Bus (9); } \\
\text { Domestic (1) }\end{array}$ \\
\hline $\begin{array}{l}\text { Newspaper, } \\
\text { Magazine, } \\
\text { Book }\end{array}$ & $17(6.1 \%)$ & $\begin{array}{l}\text { Domestic (9); University (4); } \\
\text { Commercial (4) }\end{array}$ \\
\hline Advertisement & $16(5.8 \%)$ & $\begin{array}{l}\text { Domestic (7); Commercial } \\
\text { (6); University (3) }\end{array}$ \\
\hline Other & $29(10.5 \%)$ & $\begin{array}{l}\text { Domestic (13); Commercial } \\
\text { (12); University (4) }\end{array}$ \\
\hline Total: & $277(100 \%)$ & \\
\hline
\end{tabular}

Postal letters reached the participants exclusively at their homes. Newspapers, magazines, and books were read at home, at the university, and in restaurants - with the surprising (and, as lecturers, somewhat disheartening) finding that all four of the university-located reading incidents involved recreational reading of newspapers in the library or at lectures. Ads (primarily flyers) are similarly encountered in a range of locations. The Other category is diverse, including maps, handwritten reminder notes, shopping lists, a business card and food container labels.

\subsection{Relative Date of Document Production}

The majority of $(170,61.4 \%)$ of the paper documents were produced at the time of the encounter-primarily receipts, tickets, and coupons. Approximately one-fifth (59, 21.3\%) were created within a week (bank statements, newspapers) and a scant $2.9 \%$ (8) were produced weeks, months, or years before the encounter (e.g., magazines, books). It was not clear to participants when the remainder $(40,14.4 \%)$ of the documents were produced.

\subsection{Action Taken With the Document}

More than one action can be taken with documents during an encounter (Table 4). Only $37 \%$ of paper documents are explicitly noted as being kept for future use; while $25 \%$ are immediately disposed of (frequently without even glancing at them, in the case of receipts or bus tickets). The few annotations refer to doodling, working through assignments, and in only two cases making notes in a lecture. The 'other' category is rich, including play (turning an advertising flyer into a paper plane) and document sharing (e.g., passing a draft assignment to another student).

Table 4. Action taken with the document.

\begin{tabular}{|c|c|c|}
\hline Action & $\begin{array}{l}\text { Number of } \\
\text { encounters }\end{array}$ & Percentage \\
\hline Saved / stored & 134 & $37 \%$ \\
\hline Thrown away & 90 & $24.9 \%$ \\
\hline Read or skimmed & 80 & $22.1 \%$ \\
\hline Annotated & 20 & $5.5 \%$ \\
\hline Other & 29 & $8.0 \%$ \\
\hline Not recorded & 9 & $2.5 \%$ \\
\hline Total: & 362 & $100 \%$ \\
\hline
\end{tabular}

\section{DISCUSSION}

The $24.9 \%$ of documents that were immediately discarded (Table 4) is consistent with the idea that future relevance is often uncertain $[9,11]$. The students were sure at the time of encountering the document that its usefulness was outweighed by the costs of retention. It is also consistent with the passive capture approach [4]; automatically saving some of the context of everyday life to compensate for the absence of explicit user storage actions. $61 \%$ of entries referred to paper that were generated in front of the participant; this suggests that such paper artifacts might be useful for life-logging as they are likely to embody a particular event.

The large number of receipts encountered (Section 4.2) suggests that work on electronic receipts (e.g., storage on mobile phones) might prove useful for personal archiving; permitting the storage of information that is often discarded. Interestingly as financial documents (transaction and ATM receipts) were the largest category of document production, we found no evidence of any shredding or document destruction, or other recognition of the dangers of identity theft from discarded documents. Indeed, frequently the documents are simply tossed into a nearby public rubbish bin or left in public areas of a shared living space.

Although most diary entries occurred on weekdays (Figure 1), university study-related paper artifacts were a small proportion of recorded events (Section 4.2). As computer science students the participants might be expected to be 'more digital' than others but this does support the general perception that study is less paper- 
oriented than in the past. University policies on charging for printing has likely affected the amount of paper that the participants use/encounter related to their studies; it is cheaper to consult digital copies of course handouts, and similarly printing costs incentivize students to print as little as possible.

Previous research on university (paper) note-taking typically found that nearly all students reported taking notes in lectures, and felt that task to be absolutely crucial for understanding (e.g., [3]). Our participants, however, largely rely on copies of the lecturer's PowerPoint slides, rather than creating their own lecture summaries or annotating those PowerPoint handouts. This is a massive change in student behavior that deserves further examination; manual note-taking supports learners in assimilating content in a way that printing out overhead displays cannot. Given that the interface design to digital note-taking applications can affect the note-taking process in sometimes unexpected ways, it is important to build a greater understanding of how preprepared material such as PowerPoint interacts with the learning process.

Supporting the Other category of actions taken with paper documents (Section 4.4) forms a rich vein to mine for future development of digital libraries, life-loggers, and other information applications. Paper is exceptionally well-suited to document sharing and shared annotations, in an informal and direct way that the digital cannot (yet) match. Paper also provides opportunities for amusement and enjoyment (e.g., doodling, throwing paper planes in class) that the digital information appliance community has largely been unable to address.

\section{CONCLUSIONS}

We have attempted to explore design issues for lifelogging capture and retrieval tools through a diary study of information practices involving paper artifacts. We suspect that the average 3.1 encounters per day is low-possibly an artifact of the tendency of diary study participants to under-report and further study is needed to clarify the extent to which paper-based information is becoming a rarity. Clearly, however, university study - long a paper-intensive activity - is becoming digital, and it is not yet clearly understood how digital libraries, note-taking, and digital annotation applications can be designed so as to support the rich interactions afforded by paper ([10]).

The study is exploratory and our findings clearly need triangulation across both participant groups (background, age etc.) and methodologies. Future work could also include a longitudinal analysis (including follow-up interviews about user intentions [11]), or methods that could highlight instances of unsatisfied recall of past events. Specific questions about document security and identity theft may also be worthwhile.

\section{ACKNOWLEDGMENTS}

Our thanks to the students who participated in the study.

\section{REFERENCES}

[1] Bolger, N., Davis, A., and Rafaeli, E. 2003. Diary methods: capturing life as it is lived. Annual Review of Psychology 54, 579-616.

[2] Bondarenko, O. and Janssen, R. 2005. Documents at hand: learning from paper to improve digital technologies. Proceedings of CHI '05. ACM. 121-130.

[3] Dunkel, P, and Davy, S. 1989. The heuristic of lecture notetaking: perceptions of American \& international students regarding the value \& practice of notetaking. English for Specific Purposes 8(1) 33-50.

[4] Gemmell, J., Bell, G., and Lueder, R. 2006. MyLifeBits: a personal database for everything. Communications of the ACM 49(1) 88-95.

[5] Glaser, B., Strauss, A. 1967. The Discovery of Grounded Theory. Aldine, Chicago IL.

[6] Jones G., Gurrin C., Kelly L., Byrne D. and Chen, Y. 2008. Information access tasks and evaluation from personal lifelogs. Proceedings of the 2nd International Workshop on Evaluating Information Access (EVIA 2008). Tokyo, Japan.

[7] Kim, I., Ahn, S. C., Ko, H., and Kim, H. 2006. PERSONE: personalized experience recoding and searching on networked environment. Proceedings of CARPE '06, 49-54.

[8] Liu, Z. and Stork, D.G. 2000. Is paperless really more? Communications of the ACM 43(11) 94-97.

[9] Marshall, C.C. 2007. How people manage personal information over a lifetime. In Personal Information Management (Jones, W. and Teevan, J., eds.), University of Washington Press, Seattle, WA. 57-75.

[10] Marshall, C.C., Bernheim Brush, A.J. 2004. Exploring the relationship between personal and public annotations. Proceedings of JCDL'04. ACM. 349-357.

[11] Olsson, T., Soronen, H., and Väänänen-Vainio-Mattila, K. 2008. User needs and design guidelines for mobile services for sharing digital life memories. Proceedings of MobileHCI '08. ACM. 273-282.

[12] Poupyrev, I., Oba, H., Ikeda, T., and Iwabuchi, E. 2008. Designing embodied interfaces for casual sound recording devices. In CHI '08 Extended Abstracts on Human Factors in Computing. ACM. 2129-2134.

[13] Sellen, A. J., Fogg, A., Aitken, M., Hodges, S., Rother, C., and Wood, K. 2007. Do life-logging technologies support memory for the past? An experimental study using SenseCam. Proceedings of CHI '07. ACM. 81-90.

[14] Sellen, A. J. and Harper, R.H. 2003. The Myth of the Paperless Office. MIT Press.

[15] Strodl, S., Motlik, F., Stadler, K., and Rauber, A. 2008. Personal \& solo archiving. Proceedings of JCDL '08. ACM. 115-123.

[16] Wheeler, L., and Reis, H.T. 1991. Self-recording of everyday life events; origins, types, and uses. Journal of Personality 59(3) 339-354. 